\title{
Neonatal Polycythemia Secondary to Twin to Twin Transfusion Syndrome- A Case Report
}

\author{
Ekwochi Uchenna ${ }^{1^{*}}$, Asinobi Isaac Nwabueze ${ }^{2}$ and Ndu Ikenna Kingsley ${ }^{1}$ \\ ${ }^{1}$ Department of Paediatrics, College of Medicine, Enugu State University of Science and Technology, Enugu, Nigeria \\ ${ }^{2}$ Department of Paediatrics, Enugu State University Teaching Hospital Parklane, Enugu, Nigeria
}

"Corresponding author: Ekwochi Uchenna, Lecturer and Consultant Paediatrician, Department of Paediatrics, College of Medicine, Enugu State University of Science and Technology, Enugu, Nigeria, Tel: +2348034317785; E-mail: uekwochi@yahoo.co.uk

Rec date: August 04, 2015; Acc date: August 25, 2015; Pub date: August 31, 2015

Copyright: ( 2015 Uchenna E. This is an open-access article distributed under the terms of the Creative Commons Attribution License, which permits unrestricted use, distribution, and reproduction in any medium, provided the original author and source are credited.

\begin{abstract}
Twin-twin transfusion syndrome (TTTS) is one of the most serious complications of monochorionic multiple gestations in which the receipient twin becomes plethoric while the donor twin becomes anaemic. We report the case of the 1st of a set of male twins who presented on the 2nd day of life with excessive ruddiness of the whole body noted at birth and yellowness of the eyes and face noted on the 2nd day of life. Given the comparative clinicolaboratory findings, a diagnosis of neonatal polycythemia secondary to twin to twin transfusion syndrome was made. Post partial exchange blood transfusion (PET) recovery was remarkable. This report was made because of its rarity and to raise the index of suspicion for such cases to enable proper evaluation and management.
\end{abstract}

Keywords: Polycythemia, Twin to twin transfusion syndrome, Nigeria

\section{Introduction}

Polycythemia is an abnormally high level of red blood cells. It is defined as a venous haematocrit (Hct) greater than $65 \%$ and occurs in $0.4-5 \%$ of newborn infants [1]. The symptom complex and complications of polycythemia are related to hyperviscosity of the blood. The latter has been shown to increase exponentially as Hct level rises above $42 \%$ [2]. This condition can result from placental red cell transfusion caused by delayed cord clamping (which can increase red cell mass by as much as 55\%), twin to twin transfusion syndrome, others include conditions associated with placental insufficiency viz; small for gestational age infants, pre-eclampsia, post mature infants, maternal diabetes. Twin to twin transfusion syndrome (TTTS) occurs following a unidirectional or unbalanced blood flow in the placental vascular anastomosis of a monochorionic mono- or di-amniotic twin pregnancy [2]. These anastomosis could be arteriovenous (AV), arterial to arterial (AA), venous to venous (VV). Majority of the monchorionic diamniotic placentas have AV connections [2]. Vascular anastomosis between the co-twins is common in monochorionic twins, although only a percentage ranging from 4 to 7\% develop TTT [3]. Neonatal criteria for diagnosis of TTTS include discordant weight (usually $>20 \%$ ) and haemoglobin level (usually difference of $>5 \mathrm{~g} / \mathrm{dl}$ ). However, it has been stated that hemoglobin discordance is often not present in mid gestation and advanced TTTS may be present before the threshold of $20 \%$ weight discordance is reached [3]. The recipient twin becomes plethoric while the donor twin becomes anaemic. Fetal or neonatal mortality rate of $60-100 \%$ has been documented in severe cases of TTTS, while mild to moderate cases can be associated with premature delivery [4]. Many polcythemic infants are asymptomatic, but when symptoms develop, the following features have been documented; plethora, jitteriness, jaundice, hypoglycemia, hypocalcemia, thrombocythopenia [1]. Treatment of polycythemia with partial exchange blood transfusion (PET) remains controversial [5]. At present no data supports use of PET in asymptomatic polycythemia [6], rather, close monitoring of the cardiorespiratory status, Hct and glucose levels of such patient is recommended to guide further interventions. PET is considered in symptomatic polycythemia with Hct levels above 65\%. Normal saline is the replacement fluid of choice, alternatives like plasmanate, and $5 \%$ albumin can also be used [5].

\section{Case Report}

Baby MJ (Figure 1) is the 1st of a set of male twins who presented on the 2nd day of life with complaints of excessive ruddiness of the whole body noted at birth and yellowness of both eyes and face noted on the 2nd day of life. There was no fever and baby suckles well at the breast and cries normally. Mother's blood group is $\mathrm{B}+$. He had no contact with naphthalene balls and has not ingested any drug prior to presentation.

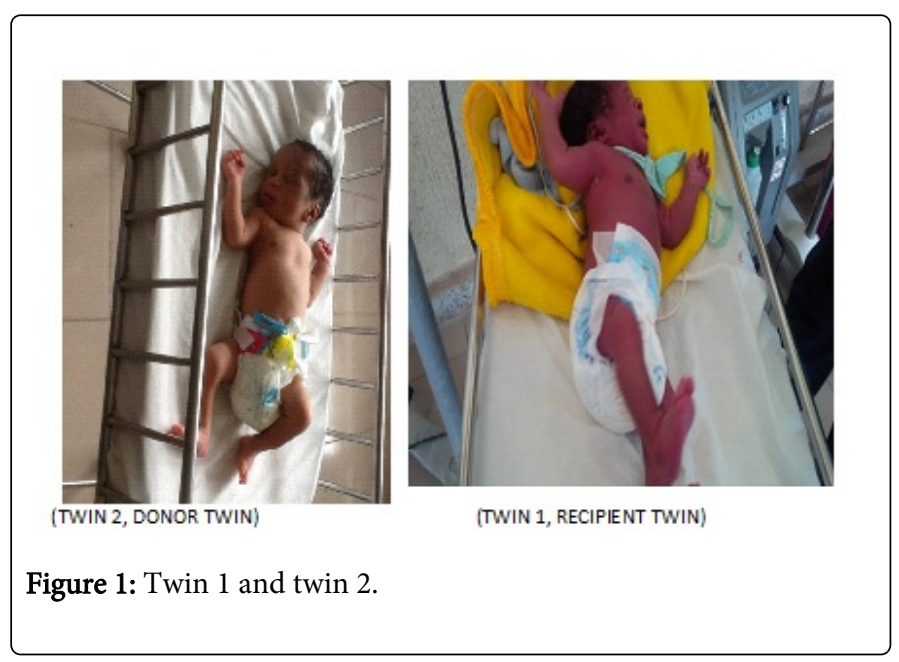


Page 2 of 3

He is the 2nd child of the family, no history of jaundice in the other siblings. Mother is 32 year old woman who booked for ANC at a gestational age of 12 weeks. She had routine antenatal investigations with normal findings, 2 doses of tetanus toxoid immunization, and was regular with her antenatal appointments and medications. She is neither a known hypertensive nor diabetics. There was neither bleeding nor febrile illness during the pregnancy. An obstetric ultrasound scan at 28 weeks revealed polyhydramnios in one of the gestational sacs with amniotic fluid index $(A F I=48.32 \mathrm{~cm})$. Labour started spontaneously at 36 weeks gestational age and the first twin (index patient) was delivered spontaneously per vagina after 6 hours then the 2nd twin thereafter. Both had good cry and activity at birth. Birth weights ( $1 \mathrm{st}$ twin $=2.75 \mathrm{~kg}, 2 \mathrm{nd}$ twin $=2.4 \mathrm{~kg}$ ). On presentation, the 1st twin was found to be plethoric all over with jaundice limited to the face, not in respiratory distress, afebrile to touch, not dehydrated and not cyanosed. Heart rate $148 \mathrm{bpm}$, Respiratory rate $54 \mathrm{cpm}$, rectal temperature 360, Occipito-frontal circumference (OFC) $33 \mathrm{~cm}$, length $48 \mathrm{~cm}$, weight at presentation $2.75 \mathrm{~kg}$. The findings on systemic examination were essentially normal. Due to the observed marked generalized plethora in the patient, an urgent Haematocrit estimation was done which showed $75 \%$ necessitating the diagnosis of neonatal polycythemia. Hence, we called for the 2nd twin (Figure 1) for comparative clinical and laboratory evaluation to rule out intrauterine twin to twin transfusion syndrome as the possible cause of polycythemia in our patient (see results in Table 1 below). Based on the observed significant difference in the haemoglobin levels, weight, and appearance of both twins, coupled with the ultrasound report of monochorinic monoamnioitic twinning with polyhydramnios, a diagnosis of neonatal polycythemia secondary to twin to twin transfusion syndrome, with our patient as recipient was substantiated.

Other investigations done on our patient include white blood cell (WBC) and differential count (Total WBC $=14.33 \times 109 / 1$, Neutrophils $=48 \%$, Lymphocytes $=45 \%$, Monocytes $=6 \%$ ) and blood group $=\mathrm{B}+$. Phototherapy was commenced and a PET with $47 \mathrm{ml}$ of Normal Saline over 90 mins was done. Haematocrit check 7 h later showed $70 \%$ necessitating a repeat PET with same volume of Normal saline and a recheck after the 2nd PET showed $62 \%$. He was observed over the next $48 \mathrm{~h}$ and discharged to the mother. On follow up visit 1week post discharge the Haematocrit check showed 59\% and baby was clinically stable.

\begin{tabular}{|c|c|c|c|c|}
\hline Parameter & Twin 1 (recipient twin) & Twin 2 (donor twin) & Lubchecho curve & Observed difference \\
\hline Appearance & Plethoric & Mildly pale & & \\
\hline Haematocrit/ (Hb) & $75 \% /(25 \mathrm{~g} / \mathrm{dl})$ & $32 \% /(10.7 \mathrm{~g} / \mathrm{dl})$ & & $43 \%(\mathrm{Hb}=14.3 \mathrm{~g} / \mathrm{dl}) ;$;ignificant difference \\
\hline Weight & $2.75 \mathrm{~kg}$ & $2.4 \mathrm{~kg}$ & $50^{\text {th }}$ percentile (AGA) & $0.35 \mathrm{~kg}(14.5 \%)$ \\
\hline Length & $48 \mathrm{~cm}$ & $48 \mathrm{~cm}$ & $50^{\text {th }}$ percentile (AGA) & No difference \\
\hline OFC & $33 \mathrm{~cm}$ & $34 \mathrm{~cm}$ & $50^{\text {th }}$ percentiles (AGA) & No significant difference \\
\hline Random blood sugar & $65 \mathrm{mg} / \mathrm{dl}$ & $95 \mathrm{mg} / \mathrm{dl}$ & & $30 \mathrm{mg} / \mathrm{dl}$ \\
\hline Serum bilirubin & $\begin{array}{l}\text { Total }=7.1 \mathrm{mg} / \mathrm{dl} \\
\text { Direct }=0.8 \mathrm{mg} / \mathrm{dl}\end{array}$ & $\begin{array}{l}\text { Total }=6.3 \mathrm{mg} / \mathrm{dl} \\
\text { Direct }=1.4 \mathrm{mg} / \mathrm{dl}\end{array}$ & & No significant difference \\
\hline Serum calcium & $1.8 \mathrm{mmol} / \mathrm{l}$ & $1.4 \mathrm{mmol} / \mathrm{l}$ & & \\
\hline Platelet count & $206 \times 10^{9} / 1$ & - & & \\
\hline
\end{tabular}

Table 1: Comparative clinical and laboratory findings in the donor and recipient twins.

\section{Discussion}

The incidence of polycythemia secondary to twin-to-twin transfusion is low. A study in the Kingdom of Saudi Arabia reported only $11 \%$ [7]. The condition is also rare in Nigeria, it was stated over a decade ago that although twin pregnancy may produce polycythemia as a result of twin-to-twin transfusion, this usually arises from monochorionic placentation, a condition which is rare in Nigeria [8]. It is hoped that this report will awaken suspicion and evaluation of such syndrome among polycythemic twins in Nigeria and other developing countries. It is also noteworthy that intrauterine malnutrition which was reported as the major factor responsible for polycythemia among twins in Nigeria [9], seems not to have outplayed in the index case as both babies were not obviously Small for Gestational Age (SGA) using the Lubchencho chart [9]. Also maternal hypertension or diabetic mellitus in pregnancy which are common risk factors for SGA were absent, while the classical differential haemoglobin level diagnostic of twin-twin transfusion syndrome was present. Perinatal asphyxia which causes an active shift of the blood volume from the placenta to the fetus and has been reported in up to $60 \%$ of PC infants was also absent in our baby [8].

Excessive ruddiness and jaundice were the presenting complaints in our patient. The former has been reported as the most obvious finding in polycythemia [10]. A study has also reported jaundice in $50 \%$ of polycythemic newborns [8], most probably due to the breakdown of an increased number of circulating red blood cells. However neurologic manifestations (jitteriness, poor feeding and lethargy) and respiratory symptoms which also have been shown to be common among the PC patients $[8,11]$ were absent in our patient. The absence of neurologic manifestations in the index case could be explained by its normoglycemic and normocalcemic state. Studies have linked neurologic manifestations in PC patients to reduced cerebral blood flow and altered tissue metabolism (hypoglycemia, hypocalcemia) [11-13]. A study reported high prevalence of respiratory symptoms especially among the premature PC newborns and those delivered via caesarean section [14]. Apart from the inherent surfactant deficiency in the preterm babies, the hyperviscosity induced by polycythemia can 
Citation: Ekwochi U, Asinobi IN, Ndu IK (2015) Neonatal Polycythemia Secondary to Twin to Twin Transfusion Syndrome- A Case Report. J Neonatal Biol 4: 189. doi:10.4172/2167-0897.1000189

Page 3 of 3

also reduce pulmonary blood flow and result in systemic hypoxia and respiratory symptoms. However, the index patient was only mildly premature and was delivered vaginally these could account for the absence of respiratory symptoms. Hypocalcemia and thrombocytopenia was reported among the PC newborns in Saudi Arabia [8]. The latter was related to elevated concentration of calcitonin gene related peptides and the former to diversion of haemopoetic progenitors towards erythropoiesis at the expense of other lineages $[15,16]$. Our patient had normal calcium and platelet levels. The difference in the ethnic and genetic makeup of the two group could be responsible.

Concerning treatment, partial exchange transfusion with normal saline was done twice in our patient. Most neonatologists perform an exchange transfusion when the peripheral venous haematocrit is above $70 \%$ in the absence of symptoms, but this is controversial [17]. For the purpose of exchange transfusion, normal saline is cheap, available and as effective as plasma. At times a second exchange may be required if saline is used for the exchange, [18] justifying the repeat PET in our patient.

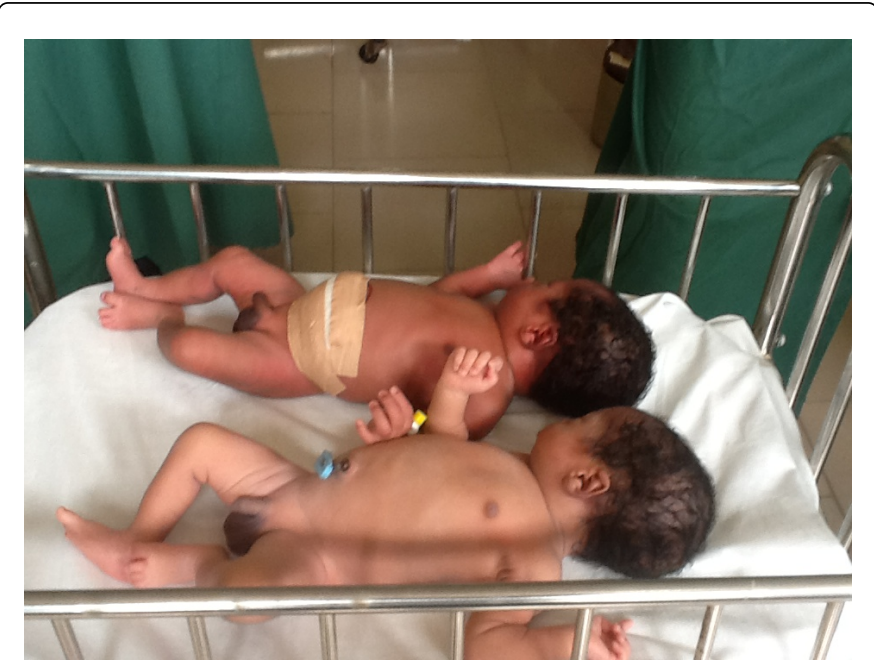

Figure 2: Both twins after the repeat PET (umbilical dressing on the recipient twin).

\section{Conclusion}

We have presented a rarely reported cause of polycythemia among twin babies in Nigeria and other developing countries. Clinicians and Neonatologists caring for polycythemic twins in these settings should develop a higher index of suspicion so as to enhance comparative evaluation and co-management of both babies.

\section{Acknowledgment}

The authors wish to express their gratitude to the Resident doctors, Nurses and other staff of Special Care Baby Unit of Enugu State University Teaching Hospital, Park lane Enugu, South-East Nigeria. Their roles were quite instrumental to the survival of our patient.

\section{References}

1. Rkin SH, Nathan DG, Ginsburg D, Look AT, Brugnara C, et al. (2009) The neonatal erythrocyte and its disorders. Nathan ans Oski's Haematology of Infancy and Childhood. (7thedn), Philadelphia, USA.

2. Jeevasankar M, Agarwal R, Chawla D, Paul VK, Deorari AK (2008) Polycythemia in the newborn. Indian J Pediatr 75: 68-72.

3. Müller MR, Wiesmüller KH, Jung G, Loop T, Humar M, et al. (2002) Lipopeptide adjuvants: monitoring and comparison of P3CSK4- and LPS-induced gene transcription. Int Immunopharmacol 2: 1065-1077.

4. www.emedicine.medscape.com/article/271752

5. www.emedicine.medscape.com/article/976319

6. Sarkar S, Rosenkrantz TS (2008) Neonatal polycythemia and hyperviscosity. Semin Fetal Neonatal Med 13: 248-255.

7. Rushdi TMA, Saad MH, Hala AY, Awatif KS, Haifa'AMA, et al., (2014) Polycythemia in Neonatal Intensive Care Unit, Risk Factors, Symptoms Pattern, and Management Controversy 2: 5-9.

8. Nylander PP (1969) The value of the placenta in the determination of zygosity--a study of 1,052 Nigerian twin maternities. J Obstet Gynaecol Br 76: 699-704.

9. Copemann CD (1975) Drug addiction: I. A theoretical framework for behavior therapy. Psychol Rep 37: 947-958.

10. www.health.vic.gov.au/neonatalhandbook/conditions/polycythaemia

11. Rosenkrantz TS (2003) Polycythemia and hyperviscosity in the newborn. Semin Thromb Hemost 29: 515-527.

12. Sarkar S, Rosenkrantz TS (2008) Neonatal polycythemia and hyperviscosity. Semin Fetal Neonatal Med 13: 248-255.

13. Dempsey EM, Barrington K (2006) Short and long term outcomes following partial exchange transfusion in the polycythaemic newborn: a systematic review.Arch Dis Child Fetal Neonatal Ed 91: F2-6.

14. Herson VC, Raye JR, Rowe JC, Philipps AF (1982) Acute renal failure associated with polycythemia in a neonate.J Pediatr 100: 137-139.

15. Saggese G, Bertelloni S, Baroncelli GI, Cipolloni C (1992) Elevated calcitonin gene-related peptide in polycythemic newborn infants.Acta Paediatr 81: 966-968.

16. Acunas B, Celtik C, Vatansever U, Karasalihoglu S (2000) Thrombocytopenia: an important indicator for the application of partial exchange transfusion in polycythemic newborn infants? Pediatr Int 42 : 343-347.

17. Goorin AM, John P Cloherty, Ann R Stark (1998) Manual of neonatal care. (4thedn), Lippincoltt Raven, USA.

18. Deorari AK, Paul VK, Shreshta L, Singh M (1995) Symptomatic neonatal polycythemia: comparison of partial exchange transfusion with saline versus plasma. Indian Pediatr 32: 1167-1171. 